\title{
Tipping the Proteome with Gene-Based Vaccines: Weighing in on the Role of Nanomaterials
}

\author{
Kristin J. Flores, ${ }^{1}$ Michael Craig, ${ }^{1}$ Adam Wanekaya, ${ }^{2}$ Lifeng Dong, ${ }^{3}$ \\ Kartik Ghosh, ${ }^{3}$ Joshua J. Smith, ${ }^{1}$ and Robert K. DeLong ${ }^{1}$ \\ ${ }^{1}$ Department Biomedical Sciences, Missouri State University, Cell and Molecular Biology Program, Professional Building, \\ Springfield, MO 65897, USA \\ ${ }^{2}$ Department Chemistry, Missouri State University, Temple Hall, Springfield, MO 65897, USA \\ ${ }^{3}$ Department Physics, Astronomy \& Materials Science, Missouri State University, Kemper Hall, Springfield, MO 65897, USA \\ Correspondence should be addressed to Kristin J. Flores, kristin377@live.missouristate.edu
}

Received 16 June 2011; Accepted 9 November 2011

Academic Editor: Chunying Chen

Copyright ( $\odot 2012$ Kristin J. Flores et al. This is an open access article distributed under the Creative Commons Attribution License, which permits unrestricted use, distribution, and reproduction in any medium, provided the original work is properly cited.

Since the first generation of DNA vaccines was introduced in 1988, remarkable improvements have been made to improve their efficacy and immunogenicity. Although human clinical trials have shown that delivery of DNA vaccines is well tolerated and safe, the potency of these vaccines in humans is somewhat less than optimal. The development of a gene-based vaccine that was effective enough to be approved for clinical use in humans would be one of, if not the most important, advance in vaccines to date. This paper highlights the literature relating to gene-based vaccines, specifically DNA vaccines, and suggests possible approaches to boost their performance. In addition, we explore the idea that combining RNA and nanomaterials may hold the key to successful gene-based vaccines for prevention and treatment of disease.

\section{Introduction}

Gene-based vaccines have been extensively studied in recent years in the hope of unlocking their potential as preventative or therapeutic tools against infectious diseases, cancer, autoimmune diseases, and other conditions resulting from molecular defects. An ideal vaccine is safe, highly immunogenic, nonintegrating, easy to manipulate, stable, and inexpensive to produce. In addition to these characteristics, a therapeutic vaccine must not be compromised by any preexisting immunity of the patient against the vaccine delivery vehicle [1-5].

Gene-based vaccines approach this ideal and demonstrate several advantages over conventional vaccines. However, gene-based vaccines, specifically DNA vaccines, have produced disappointing results in human clinical trials, suggesting that there is something missing from this puzzle. The gene-based approach requires a performance boost before these vaccines will be suitable for the clinic. One approach may be to explore the benefits of using RNA vaccines rather than DNA vaccines. This approach raises the issue of stability and delivery, which in turn suggests potential roles for nanomaterials as vital components in gene-based vaccines.

Nanomaterials harness the power to act as stabilizing delivery vehicles for gene-based vaccines. With their small size and large surface area, nanomaterials have the ability to deliver a high payload of DNA or RNA [6], thus increasing the efficacy of gene-based vaccines. Among the most common nanomaterials studied for vaccine delivery are metallic and magnetic nanoparticles, nanoliposomes, and dendrimers [7]. This paper touches on the recent developments in gene-based vaccines and their advantages in terms of inducing both a cellular and humoral response. The idea that RNA, along with nanomaterials, could play a critical role in the development of the ideal gene-based vaccine is also discussed, as well as the nanomaterials' potential advantage in terms of binding, stabilization, and delivery. 


\section{Overview of Current Approaches in Vaccines}

Conventional vaccines are composed of recombinant proteins, live-attenuated viruses, purified bacterial or virus components, or conjugates of proteins with polysaccharide carriers [3]. These vaccines have a long track record and have been widely used to eradicate numerous infectious diseases, such as smallpox, poliomyelitis, and diphtheria [8]. However, conventional vaccines suffer from numerous problems. For example, recombinant protein vaccines are extremely costly to produce, often tedious to purify, and do not effectively induce $\mathrm{CD}^{+} \mathrm{T}$ cells $[3,4]$. Conventional vaccines that employ recombinant viruses have their own risks, including reversion, inadvertent spread of infection, insertional mutagenesis, and the induction of autoimmunity [3-5]. In addition to these risks, there are numerous diseases for which conventional vaccines are not effective; alternatively, gene-based vaccines demonstrate tremendous promise in several of these areas, including cancer [7, 9], tuberculosis [10, 11], HIV [12], and malaria [13, 14].

\section{DNA Vaccines}

3.1. Delivery. The concept behind DNA vaccines was developed by Wolff et al. using reporter genes to show that the types of cells that are transfected are dependent on the route and method of delivery [15]. DNA vaccines can be delivered to cells by several different routes, including, but not limited to, intramuscular, intraepidermal, intravenous, intranasal, oral, and subcutaneous delivery $[1,4,16,17]$. Delivery methods are numerous and include injection, tattooing, particle-mediated biolistic bombardment, electroporation, laser, and ultrasound. Intramuscular injection is the most common method, which leads predominantly to transfection of myocytes $[4,15,17,18]$.

In the search for a delivery method that induces a stronger immune response, much attention has been given to particle-mediated biolistic bombardment via the gene gun. For this method, recombinant plasmid DNA, containing the gene coding for a specific antigen, is affixed to an inert particle, such as a gold microparticle, and forced into the target cells by high-pressure gun. Delivery by the gene gun has been employed in the direct transfection of epidermal keratinocytes, Langerhans cells, and dendritic cells $[19,20]$. Studies performed by Mendez et al. demonstrated that the DNA vaccine dosage required to induce full protection in mice challenged with Leishmania major was five times smaller using the gene gun than subcutaneous or intramuscular injection [21]. Interestingly, another study reported that approximately 100 -fold less DNA is required for an equivalent immune response than that achieved with needle injection in mice [22]. Both these studies clearly indicate that the efficacy of DNA vaccines is improved when delivered by particle-mediated biolistic techniques rather than by intramuscular injection.

3.2. Mechanism of Action. Although the exact mechanisms and pathways are still under investigation, DNA vaccines are believed to be relatively simple tools for transfection, leading to antigen production with the ultimate goal of an immune response. The plasmid DNA that encodes the desired antigen is under the control of a mammalian promoter and can be produced seamlessly in bacteria [23]. The optimized, desired gene sequence is delivered by one of several methods, and the plasmid is transported to the nucleus where it uses the host's transcriptional and translational machinery to produce the desired protein product. Proteases cleave the protein into peptides, which can be presented subsequently by the MHC class I molecules to induce the $\mathrm{CD} 8^{+} \mathrm{T}$ lymphocytes $[3,4,24,25]$. The dendritic cells endocytose then express the antigen via MHC class I and MHC class II molecules, thereby inducing both the $\mathrm{CD} 4^{+}$and $\mathrm{CD} 8^{+} \mathrm{T}$ lymphocyte populations $[19,20]$. The major advantage of this vaccination approach is endogenous expression of the encoded antigen, resulting in either direct processing of the protein in an antigen presenting cell or in cross-presentation, as illustrated in Figure 1 [19-29].

3.3. Potential Issues. The general consensus in the current literature is that DNA vaccines are considered safe because they are not living and do not replicate. Yet there are a few concerns that have been raised, such as the induction of autoimmunity against the patient's DNA [23,30], as well as undirected integration, which may lead to insertional mutagenesis by inducing oncogenes or silencing tumor suppressor genes [16, 31]. During plasmid production, antibiotic resistance genes are used as a selection tool, and this use has raised concern that antibiotic resistance could be transferred to the patient's enteric bacteria [16, 32]. To eliminate this concern entirely, there are other selection methods that are available, including auxotrophy complementation [33], repressor titration [34], and proteinbased antidote/poison selection strategies [35]. Despite these concerns, DNA vaccines have an impeccable safety record in preclinical work and clinical trials $[16,23]$. It is because of this record that these potential safety concerns, although closely monitored, have become secondary to the attempts to enhance the efficacy and immunogenicity of DNA vaccines.

3.4. Enhancing DNA Vaccines. There are many possible approaches to enhancing the efficacy and immunogenicity. As previously mentioned, the route and method of delivery can have a profound effect on the outcome of vaccination. Codon optimization, promoter sequences, introns, enhancers, polyadenylation signals, and unmethylated cytosine-guanine dinucleotide $(\mathrm{CpG})$ repeats can be modified within the plasmid to yield maximum expression of the protein product $[32,36-41]$. Another popular option is using formulation adjuvants. The most common of these include proteins, conjugates of small molecules, liposomes, and micro- and nanoparticles $[3,6,7]$. The answer to the problem of enhancing the efficacy and immunogenicity of DNA vaccines likely resides in a novel combined approach. The goal is to enhance the benefits by an effective delivery system combined with various adjuvants. Nanomaterials, which can act as both the delivery vehicle and stabilizing 


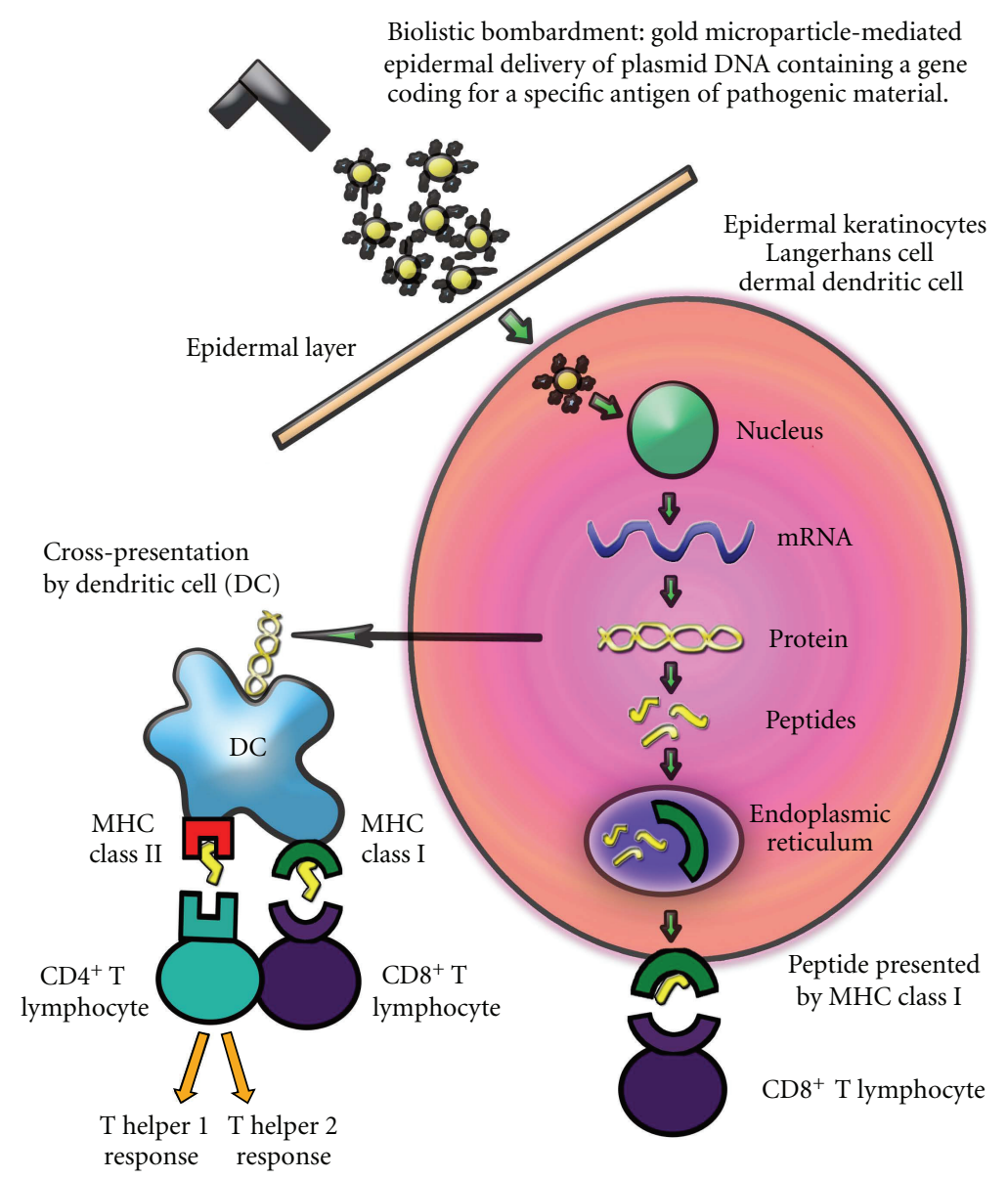

FIgURE 1: Basic mechanism of action for DNA vaccines delivered by particle-mediated biolistic bombardment and the resulting immune response. Using DNA attached to the gold particles provides increased stability and higher payload, and the dosage requirement is significantly lower than that for intramuscular injection.

adjuvant $[7,42]$, are likely to play a crucial role and will be discussed later.

\section{RNA Vaccines}

4.1. Simplified Mechanism of Action. One major advantage of RNA vaccines is that the RNA acts in the cytoplasm and is translated directly to proteins, therefore bypassing nuclear localization and transcription necessary for DNA vaccines [3, 4]. Just as in DNA vaccines, RNA vaccines activate both the cellular and humoral pathways of the immune response [4252]. Other advantages of RNA are that it is easily degraded and is rapidly cleared from the tissue, resulting in greater control of the outcome [47]. This situation is in contrast to DNA vaccines that carry the risk of insertional mutagenesis, thus altering the host cell gene expression in an undesirable and uncontrollable fashion.

A substantial amount of research exists regarding the use of RNA in diverse forms, including messenger RNA, short interfering RNA, and splice-site switching oligomers [4252], some of which are discussed later in this paper. There has also been a surge in the interest in double-stranded RNA, especially polyinosinic:polycytidilic acid, also known as poly I:C. Poly I:C is a promising adjuvant for vaccines, especially cancer, since it is a potent immunostimulant and powerful activator of the toll-like receptor-3 (TLR3) and melanoma differentiation-associated protein-5 (MDA5) $[42,53]$.

4.2. Stability in Storage and Delivery. Another widespread concern is that RNA is too unstable for storage and delivery to be an effective player in gene therapy. Although RNA is unstable, new evidence shows that it may be better suited for vaccines than researchers had originally thought $[43,44]$. Just as the difficulties pertaining to RNA stability during storage are being solved, solutions to problems associated with stability during delivery are being addressed. Although a few studies have demonstrated that even unprotected RNA may be able to induce cytotoxic $\mathrm{T}$ lymphocyte responses in patients $[5,51-55]$, there are ongoing efforts to stabilize RNA molecules in order to make delivery more efficient and enhance the effect.

RNA vaccines avoid many of the potential problems with DNA vaccines, and they require a less complicated pathway to exert their effect. RNA vaccines may very well 
be essential to the success of future vaccine strategies for fighting infectious diseases, cancer, and other conditions caused by molecular defects. However, just as with DNA vaccines, there are some difficulties that need to be overcome before RNA vaccines can be optimized into the ideal genebased vaccine. Stability and delivery are the main targets for optimization, and nanomaterials offer promising candidates for these targets.

\section{Nanomaterials: The Missing Piece to the Puzzle}

The term nanomaterials encompasses a broad and fascinating range of molecules and compounds. However, for the purposes of this paper, the focus will be on select nanomaterials with the ability to enhance the delivery and effect of gene-based vaccines, especially RNA vaccines. Due to their unique physicochemical properties, nanomaterials are promising platforms for gene-based vaccines. They offer many biomedical advantages, including increased stability, efficient delivery, desirable biodistribution, and specific cell targeting, just to name a few [53]. The uptake of nanomaterials by cells, specifically cells of the immune system, is influenced by numerous factors [53, 56-60]. Different nanomaterials and their distinct characteristics, such as size, morphology, and surface chemistry, play a role in the specific internalization pathway, the effect of the nanomaterial on the cell, and its biodistribution [56-59].

There are numerous approaches and advantages for nanomaterial-mediated delivery of nucleic acids. Compared to viral delivery systems for gene-based vaccines, nanomaterial-mediated delivery systems offer a higher payload and greater stabilization potential. Often when nanomaterials are complexed with biomolecules, the result is an improvement in stability, biocompatibility, and retention of other desirable characteristics for both the nanoparticle and the biomolecule $[42,55]$. These improvements are important for delivery into the body where exposure to physiological fluids, nucleases, and other biological components create endless obstacles for the nanomaterial:nucleic acid complex to reach its target.

5.1. Gold Nanoparticles. Like DNA vaccines, RNA can be affixed onto functionalized gold micro- or nanoparticles and delivered by particle-mediated biolistic bombardment $[48,56,57]$. The surface of the gold can be functionalized with specific tumor targeting agents, which are often a ligand for a specific receptor on the target cell surface not expressed on other cells. This targeting agent increases the transfection efficiency of the vaccine. Qui et al. used the functionalized gold particle-mediated gene gun to deliver three different mRNA molecules into several tissue types. Protein expression from RNA transcripts of the three reporter genes was detected after in vitro delivery in monolayer and suspension cell cultures, and in rat liver tissues, mouse liver, and epidermal tissues after in vivo delivery [48].
Experiments performed by Sandhu et al. indicate that gold nanoparticles were eight times more efficient at condensing and delivering nucleic acid compared to the commonly used polyethyleneimine polymer [57]. Protamine, an arginine-rich protein, can be used in conjunction with the RNA and gold nanoparticles. Protamine, which is necessary for DNA condensation in spermatogenesis, also enhances the stability of the RNA and protects it from degradation by RNases by condensing the RNA into a nanoparticle. In addition to its function as a stabilizer for RNA, protamine is known to be a cell-penetrating molecule and acts as a strong danger signal to the immune system, activating the immune response through a MyD-88-dependent pathway [46]. Delong et al. reported that combining the nucleic acid: protamine complex with gold nanoparticles forms a nanocomplex that can be analyzed by dynamic laser light scattering particle analysis (DLLS), gel shift mobility assays, and fluorescence [55]. In other work, the researchers reported that the RNA structure and vaccine bioactivity were retained even after exposure to physical, chemical, and thermal degradation. They demonstrated that the biological activity of the RNA was conserved by using a splicesite switching assay and delivering siRNA against a key cancer target, B-Raf [55]. A schematic of the nanocomplex formation for siRNA delivery is shown in Figure 2. It is important to note that condensing the RNA with protamine and attaching it to gold nanoparticles may be useful for numerous types of RNA, including siRNA, antisense RNA, and messenger RNA.

5.2. Nanoliposomes. Another common method of stabilization is to use liposomes, or nanoliposomes, as protective carriers of nucleic acids. Liposomes are cationic lipids that form stable complexes with negatively charged nucleic acids through electrostatic interactions [49]. The association of nucleic acids with lipids or polymers results in positively charged particles small enough for entry through the negatively charged plasma membrane by endocytosis, resulting in the formation of a double-bilayer vesicle. In the process of maturation of the endosome into a lysosome, the endosome may rupture, and the nucleic acid cargo could be released into the cytoplasm. Translocation to the nucleus might result in gene expression for DNA [49-51]. In addition to cellular entry by endocytosis, as illustrated in Figure 3, nanoliposomes may also fuse with the membrane and unload their cargo directly into the cytosol.

Changes in the surface charge on nanoliposomes can improve delivery and cellular uptake. Liposomes themselves can be immunostimulatory, a characteristic that could enhance the immunogenicity of the vaccine, or they can be coated with a polymer, such as derivatives of polyethylene glycol and others, to prevent recognition by the immune system $[3,7,50,51]$. The data suggest that antigenpresenting cells are better able to sequester nanoliposomes than larger-sized liposomes. Cationic liposomes are much more potent in eliciting an immune response than anionic or neutral liposomes. The surface of the liposome can also be modified with various ligands to allow targeting to specific tissues or cells $[49,50]$. 


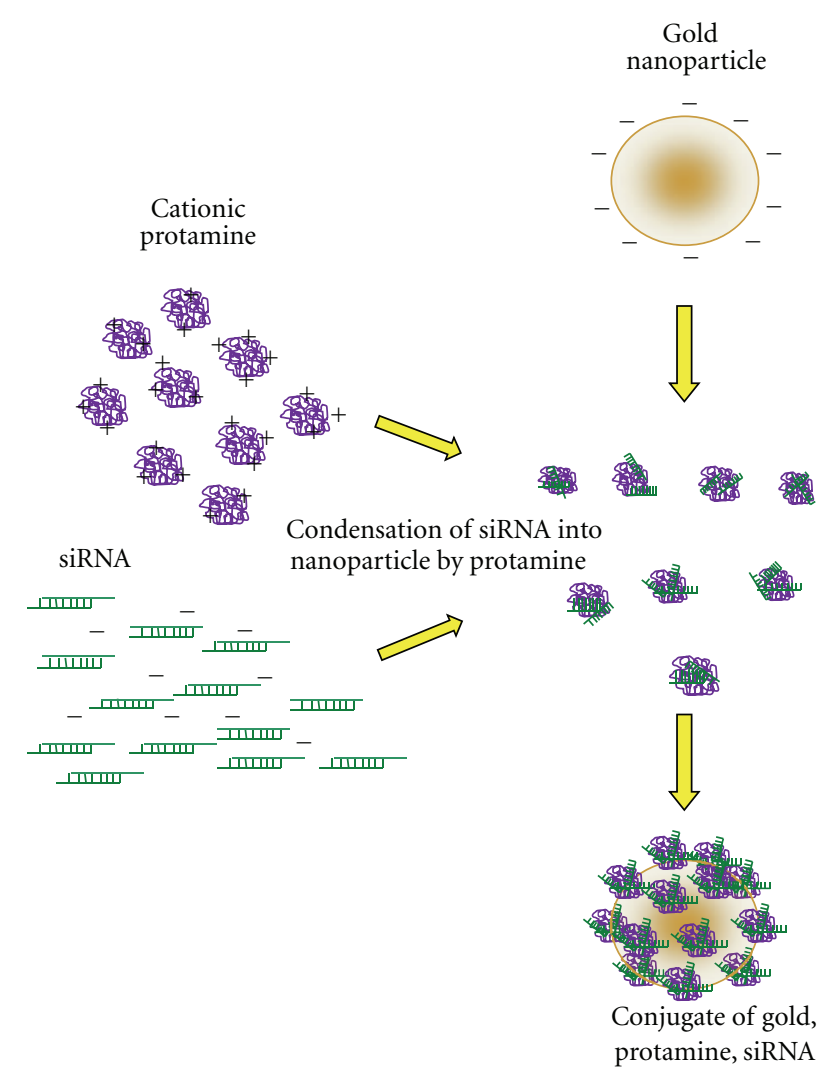

FIGURE 2: Graphical representation of the formation of complexes between gold nanoparticles, protamine, and siRNA. The cationic protamine condenses the RNA into nanoparticles, assisting its stabilization and protecting it from degradation. The protamine: RNA complexes then bind to the surface of the gold nanoparticle, which confers more stability and protection.

5.3. Dendrimers. Dendrimers are highly branched synthetic polymers with a high-density positive surface charge. Polyamidoamine (PAMAM) dendrimers are able to condense nucleic acids into a nanoparticle; such condensation has been shown to protect them from nuclease degradation [7, 55]. Dendrimers are also known to be cellpenetrating molecules. There are different generations of PAMAM dendrimers, and this parameter, along with the size-to-charge ratio, is important in the formation of stable nanoparticles [61]. An increase in the PAMAM dendrimer generation has been correlated to an increase in the delivery efficiency, yet it is well-known that the higher generation dendrimers are also cytotoxic [59-65]. The nucleic acid binding characteristics must be carefully balanced with the cytotoxicity, often executed by functionalization of the dendrimer branches. An example of this functionalization is amine acetylation of PAMAM dendrimers. This acetylation decreases the interaction of siRNA with the dendrimers, thereby facilitating the unpackaging of siRNA in target cells. The increased release of the siRNA cargo from the dendrimer in the cell leads to an increase in transfection efficiency $[61,64]$.
Different generations of PAMAM dendrimers have been complexed to other nanoparticles to stabilize and deliver DNA and RNA [61]. Pan et al. complexed magnetic nanopartcles to PAMAM dendrimers and antisense survivin oligonucleotides. Human cells from breast and liver tumors were incubated with these nanocomplexes and subsequently, the samples were subjected to analysis by 3-(4,5-dimethylthiazol-2-yl)-2,5-diphenyltetrazolium bromide (MTT), quantitative RT-PCR, Western blot, and transmission electron microscopy. The results demonstrated that within 15 minutes, the nanocomplexes had entered the tumor cells and significant downregulation of the targeted survivin gene and its protein product were observed. The authors reported in addition that cell proliferation was inhibited in a dose-dependent and time-dependent manner [61].

5.4. Nanomaterials and Nanotoxicity. Nanomaterials can have very different physicochemical properties compared with bulk materials of the same chemical composition. Some of these properties (small size, large surface area, etc.) that make nanomaterials desirable for biomedical use also generate potential risks for cytotoxicity. Results from numerous experiments with various nanomaterials suggest that size, surface area, morphology, surface chemistry, and chemical composition are the major determinants of nanomaterial uptake and cytotoxicity $[54,56-65,67,68]$. Just like many other nanosciences, the study of nanotoxicity has become an area of intense focus; however, researchers are still trying to develop an improved understanding of the pathways and mechanisms involved.

Experiments performed by Kroll et al. [62] demonstrated the influence of physicochemical properties on cytotoxicity by using different groups of engineered nanoparticles with the same chemical composition. For example, some of the samples used were prepared using identical particle preparations, but one sample was dispersed at a different $\mathrm{pH}$. Other samples varied in their surface area, particle size, or surface chemistry. The researchers used three in vitro assays on ten different cell lines to monitor different stages of cytotoxicity: oxidative stress, cellular metabolic activity, and cell death. The outcome of this study, although too extensive to elaborate here, confirms that in vitro toxicity cannot be linked to a single, specific physicochemical property of the nanomaterial. Kroll et al. suggest that the response is due to the combined effects of the size, morphology, surface chemistry, and chemical composition of the nanomaterial, yet the effects are also cell-type dependent, and the results vary depending on the endpoint used to measure toxicity.

Because dendrimers have enormous potential as delivery vehicles for therapeutic nucleic acids, it is important to harness that potential while still balancing the cytotoxic effects. There are numerous approaches to reducing the cytotoxicity while maintaining optimal function, including binding hydrophilic polymers to the outermost branches of the dendrimers, creating half-generation dendrimers, and modifying some of the cationic amine groups to neutralize them [59-65]. 


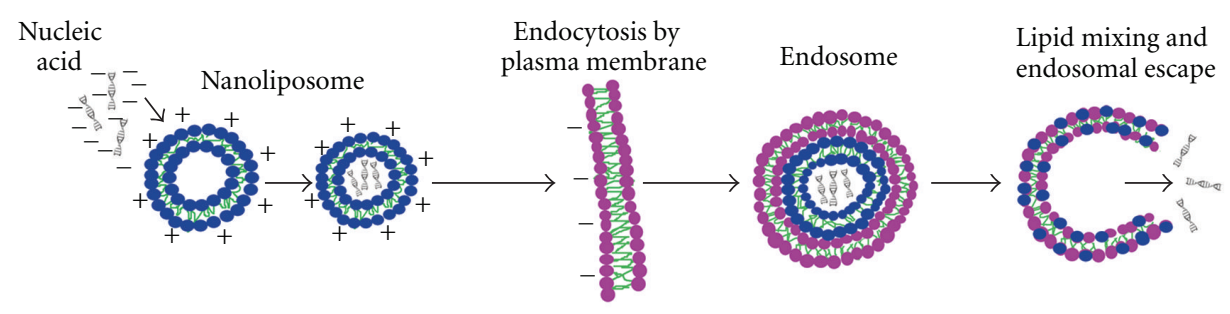

FIGURE 3: Nanoliposome-mediated endocytosis of therapeutic nucleic acids. After escape from the endosome, if the nucleic acid cargo is DNA, then nuclear translocation will occur, permitting the DNA to be transcribed and subsequently translated. If the nucleic acid cargo is RNA, it is translated in the cytoplasm.

TABLE 1: Summary of current data and future direction for gene-based vaccines.

\begin{tabular}{|c|c|c|c|}
\hline & DNA Vaccines $[1-42,66]$ & RNA Vaccines $[5,42-55]$ & $\begin{array}{l}\text { Future Direction: RNA and Nano- } \\
\text { materials }[6,53,55-65,67-77]\end{array}$ \\
\hline Design & $\begin{array}{l}\text { Relatively easy, inexpensive, and } \\
\text { quick to construct. Easy to } \\
\text { manipulate. Does not require cold } \\
\text { chain. }\end{array}$ & $\begin{array}{l}\text { Relatively easy, inexpensive, and quick to } \\
\text { construct. Can be produced in large } \\
\text { amounts in vitro from DNA template. }\end{array}$ & $\begin{array}{l}\text { Functionalized nanomaterials can } \\
\text { be conjugated to further stabilize } \\
\text { RNA and to increase penetration. }\end{array}$ \\
\hline Delivery & $\begin{array}{l}\text { IM injection is most common, but } \\
\text { often requires prime/boost. Biolistic } \\
\text { bombardment with DNA-coated } \\
\text { gold microparticles is currently } \\
\text { most efficient. Needle-free delivery } \\
\text { via Bioinjector. }\end{array}$ & $\begin{array}{l}\text { Currently, there is no standard delivery } \\
\text { method; IM injection is most common. } \\
\text { Liposome carriers can also be used. }\end{array}$ & $\begin{array}{l}\text { Gene gun delivery of RNA conju- } \\
\text { gated with dendrimers and various } \\
\text { nanoparticles as stabilizing delivery } \\
\text { vehicles. }\end{array}$ \\
\hline Stability & $\begin{array}{l}\text { Generally stable at room } \\
\text { temperature. Long shelf life. }\end{array}$ & $\begin{array}{l}\text { Unstable for storage unless oxidation, } \\
\text { hydrolysis, and contact with nucleases are } \\
\text { prevented. Quickly degraded in } \\
\text { physiological fluid, although studies show } \\
\text { unprotected RNA can induce immune } \\
\text { response. }\end{array}$ & $\begin{array}{l}\text { Complexing the RNA with multi- } \\
\text { ple nanomaterials can have a com- } \\
\text { pounding effect to increase stability } \\
\text { for storage and delivery. }\end{array}$ \\
\hline Safety & $\begin{array}{l}\text { Considered relatively safe, though } \\
\text { there is theoretical risk of } \\
\text { insertional mutagenesis after } \\
\text { integration, induction of } \\
\text { autoimmunity, and transfer of } \\
\text { antibiotic resistance. }\end{array}$ & $\begin{array}{l}\text { Rapidly cleared from tissue and does not } \\
\text { need to enter nucleus; therefore, there is } \\
\text { no risk of insertional mutagenesis after } \\
\text { integration, induction of autoimmunity, } \\
\text { or transfer of antibiotic resistance. }\end{array}$ & $\begin{array}{l}\text { Continue researching the effect of } \\
\text { shape, size, and surface chemistry on } \\
\text { biocompatibility and cellular inter- } \\
\text { actions of various nanomaterials. }\end{array}$ \\
\hline Immunogenicity & $\begin{array}{l}\text { Activate both cellular and humoral } \\
\text { pathways. Poor result in human } \\
\text { clinical trials. Must be transported } \\
\text { to the nucleus in order to exert } \\
\text { biological effect. }\end{array}$ & $\begin{array}{l}\text { Activate both cellular and humoral } \\
\text { pathways. No need to cross nuclear } \\
\text { membrane to exert its biological effect. } \\
\text { No need to be replicated or transcribed. }\end{array}$ & $\begin{array}{l}\text { Complex RNA to nanomaterials that } \\
\text { recognize and target specific cells. } \\
\text { Continue research on nanomaterials } \\
\text { that penetrate the cell membrane } \\
\text { with adverse cellular effects. }\end{array}$ \\
\hline
\end{tabular}

Gold nanoparticles are generally considered safe and biocompatible [68-72]. Studies performed by Chithrani et al. indicate that $50 \mathrm{~nm}$ spheres of citric acid ligand-stabilized gold nanoparticles are endocytosed by HeLa cells more rapidly than $14 \mathrm{~nm}$ and $74 \mathrm{~nm}$ spheres [68]. Goodman et al. studied cationic and anionic gold nanoparticles and determined that the cationic particles exhibit moderate toxicity, while anionic gold particles were nontoxic [69]. The researchers suggested that the mechanism for toxicity was related to the initial electrostatic binding of the cationic particles to the negatively charged cell membrane, while the anionic particles were repelled from the cell surface, thereby reducing the toxicity. In experiments studying the effect of the morphology of gold nanoparticles on uptake and toxicity, again executed by Chithrani et al., it was determined that nanorods and nanospheres are both taken up by HeLa cells, although nanorods were taken up at a much slower rate [70]. Other nanomaterials, such as iron oxide [73, 74], zinc oxide [75-77], silicon dioxide [78, 79], quantum dots [80], and many more are under investigation for their potential as biocompatible gene-delivery vehicles.

\section{Summary}

In summary, the search for an ideal vaccine has led to genebased approaches because they have numerous advantages over conventional vaccines. The fundamental advantage of gene-based vaccines is that they induce both the cellular and humoral pathways of the immune system, a capability 
that conventional vaccines have been unable to achieve. The problems with the performance of DNA vaccines have given rise to the idea of using various forms of RNA in place of DNA. Although RNA offers definite advantages over DNA for use in vaccines, this approach generates new questions relating to RNA stability for storage and delivery. Many of the concerns about RNA stability have been addressed, and using nanomaterials as stabilizing delivery vehicles could be essential to the solution of these issues. Table 1 summarizes the current advantages and challenges not only of DNA and RNA vaccines, but also of RNA vaccines enhanced with nanomaterials, which we see as the future of gene-based vaccines.

\section{Conclusion}

On the horizon, nanomaterials may tip the balance and finally be able to deliver on the promise of gene vaccines and achieve a beneficial change in the proteome. RNA vaccines, which can be robustly translated into protein antigens that can more effectively elicit an immunotherapeutic Th1 and Th2 response, represent a powerful and promising solution for cancer and infectious diseases that have eluded cures so far. Critical to this solution will be identifying nanomaterials that permit RNA entry into cells, bypassing the cell membrane while at the same time protecting the RNA from many nucleases that can destroy it. This route could potentially enable a more prolonged and sustained expression of the encoded proteins, and hence, weighing in more heavily on the overall proteomic pattern on the key cells of the immune system. With further work, it may be possible to construct RNA nanoconjugates having these key capabilities built into them.

At present, there is a massive effort to identify nanomaterials that, while providing the above advantages, elicit the desired alterations in the cellular proteome, but which do not have untoward, off-target, or other undesirable effects. The proteome is complex and our understanding of how it can be modulated selectively is evolving. The effects of these bionanoconjugates on the binding, stabilization, and delivery of DNA and RNA vaccines, in addition to how these novel bionanomaterials "tip the proteome" is perhaps one of the critical scientific questions of the 21 st century.

\section{Acknowledgments}

The authors would like to thank our collaborators, particularly Dr. Richard Garrad and Dr. Christopher Field, for their generous support, encouragement, and helpful discussions. R. K. Dlong, K. Ghosh, M. Craig, and A.Wanekaya are supported by an AREA/R15 Grant from the National Cancer Institute entitled, "Anti-Cancer RNA Nanoconjugates" (1 R15 CA139390-01).

\section{References}

[1] J. J. Donnelly, J. B. Ulmer, and M. A. Liu, "Minireview: DNA vaccines," Life Sciences, vol. 60, no. 3, pp. 163-172, 1996.
[2] J. J. Donnelly, A. Friedman, D. Martinez et al., "Preclinical efficacy of a prototype DNA vaccine: enhanced protection against antigenic drift in influenza virus," Nature Medicine, vol. 1, no. 6, pp. 583-587, 1995.

[3] M. Vajdy, I. Srivastava, J. Polo, J. Donnelly, D. O'Hagan, and M. Singh, "Mucosal adjuvants and delivery systems for protein-, DNA- and RNA-based vaccines," Immunology and Cell Biology, vol. 82, no. 6, pp. 617-627, 2004.

[4] W. W. Leitner, H. Ying, and N. P. Restifo, "DNA and RNAbased vaccines: principles, progress and prospects," Vaccine, vol. 18, no. 9-10, pp. 765-777, 1999.

[5] K. L. Jones, D. Drane, and E. J. Gowans, "Long-term storage of DNA-free RNA for use in vaccine studies," BioTechniques, vol. 43, no. 5, pp. 675-681, 2007.

[6] R. K. DeLong, R. Knowle, and A. Werner, "R4 peptide-pDNA nanoparticle coated HepB vaccine microparticles: sedimentation, partitioning, and spray freeze dry bioprocesses," Journal of Nanoscience and Nanotechnology, vol. 6, no. 9-10, pp. 27832789, 2006.

[7] A. Bolhassani, S. Safaiyan, and S. Rafati, "Improvement of different vaccine delivery systems for cancer therapy," Molecular Cancer, p. 3, 2011.

[8] T. D. Nandedkar, "Nanovaccines: recent developments in vaccination," Journal of biosciences, vol. 34, no. 6, pp. 9951003, 2009.

[9] C. P. Mao and T. C. Wu, "Inhibitory RNA molecules in immunotherapy for cancer," Methods in Molecular Biology, vol. 623, pp. 325-339, 2010.

[10] T. Xue, E. Stavropoulos, M. Yang et al., "RNA encoding the MPT83 antigen induces protective immune responses against Mycobacterium tuberculosis infection," Infection and Immunity, vol. 72, no. 11, pp. 6324-6329, 2004.

[11] M. Ingolotti, O. Kawalekar, D. J. Shedlock, K. Muthumani, and D. B. Weiner, "DNA vaccines for targeting bacterial infections," Expert Review of Vaccines, vol. 9, no. 7, pp. 747-763, 2010.

[12] X. Ma, D. Wang, Y. Wu et al., "AIDS treatment with novel anti-HIV compounds improved by nanotechnology," AAPS Journal, vol. 12, no. 3, pp. 272-278, 2010.

[13] S. Scheiblhofer, R. Weiss, and J. Thalhamer, "Genetic vaccination approaches against malaria based on the circumsporozoite protein," Wiener Klinische Wochenschrift, vol. 118, no. 3, pp. 9-17, 2006.

[14] R. Wang, D. L. Doolan, T. P. Le et al., "Induction of antigenspecific cytotoxic T lymphocytes in humans by a malaria DNA vaccine," Science, vol. 282, no. 5388, pp. 476-480, 1998.

[15] J. A. Wolff, R. W. Malone, P. Williams et al., "Direct gene transfer into mouse muscle in vivo," Science, vol. 247, no. 4949 I, pp. 1465-1468, 1990.

[16] M. A. Kutzler and D. B. Weiner, "DNA vaccines: ready for prime time?" Nature Reviews Genetics, vol. 9, no. 10, pp. 776788, 2008.

[17] S. Manam, B. J. Ledwith, A. B. Barnum et al., "Plasmid DNA vaccines: tissue distribution and effects of DNA sequence, adjuvants and delivery method on integration into host DNA," Intervirology, vol. 43, no. 4-6, pp. 273-281, 2000.

[18] T. M. Fu, J. B. Ulmer, M. J. Caulfield et al., "Priming of cytotoxic T lymphocytes by DNA vaccines: requirement for professional antigen presenting cells and evidence for antigen transfer from myocytes," Molecular Medicine, vol. 3, no. 6, pp. 362-371, 1997.

[19] J. J. Donnelly, M. A. Liu, and J. B. Ulmer, "Antigen presentation and DNA vaccines," American Journal of Respiratory and Critical Care Medicine, vol. 162, no. 4, pp. S190-S193, 2000. 
[20] A. Porgador, K. R. Irvine, A. Iwasaki, B. H. Barber, N. P. Restifo, and R. N. Germain, "Predominant role for directly transfected dendritic cells in antigen presentation to CD8+ T cells after gene gun immunization," Journal of Experimental Medicine, vol. 188, no. 6, pp. 1075-1082, 1998.

[21] S. Méndez, Y. Belkaid, R. A. Seder, and D. Sacks, "Optimization of DNA vaccination against cutaneous leishmaniasis," Vaccine, vol. 20, no. 31-32, pp. 3702-3708, 2002.

[22] N. A. Doria-Rose and N. L. Haigwood, "DNA vaccine strategies: candidates for immune modulation and immunization regimens," Methods, vol. 31, no. 3, pp. 207-216, 2003.

[23] M. A. Liu and J. B. Ulmer, "Human Clinical Trials of Plasmid DNA Vaccines," Advances in Genetics, vol. 55, pp. 25-40, 2005.

[24] M. Howarth and T. Elliott, "The processing of antigens delivered as DNA vaccines," Immunological Reviews, vol. 199, pp. 27-39, 2004.

[25] K. L. Rock and L. Shen, "Cross-presentation: underlying mechanisms and role in immune surveillance," Immunological Reviews, vol. 207, pp. 166-183, 2005.

[26] C. A. Janeway, P. Travers, M. Walport, and M. Slomchik, "The immune system in health \& disease," in Immunobiology: The Immune System in Health and Disease, pp. 613-662, 6th edition, 2005.

[27] R. Wang, D. L. Doolan, T. P. Le et al., "Induction of antigenspecific cytotoxic T lymphocytes in humans by a malaria DNA vaccine," Science, vol. 282, no. 5388, pp. 476-480, 1998.

[28] N. P. Restifo, H. Ying, L. Hwang, and W. W. Leitner, "The promise of nucleic acid vaccines," Gene Therapy, vol. 7, no. 2, pp. 89-92, 2000.

[29] M. J. Roy, M. S. Wu, L. J. Barr et al., "Induction of antigenspecific CD8+ T cells, T helper cells, and protective levels of antibody in humans by particle-mediated administration of a hepatitis B virus DNA vaccine," Vaccine, vol. 19, no. 7-8, pp. 764-778, 2000.

[30] D. M. Klinman, F. Takeshita, S. Kamstrup et al., "DNA vaccines: capacity to induce auto-immunity and tolerance," Developments in Biologicals, vol. 104, pp. 45-51, 2000.

[31] R. L. Sheets, J. Stein, T. S. Manetz et al., "Biodistribution of DNA plasmid vaccines against HIV-1, Ebola, Severe Acute Respiratory Syndrome, or West Nile virus is similar, without integration, despite differing plasmid backbones or gene inserts," Toxicological Sciences, vol. 91, no. 2, pp. 610-619, 2006.

[32] J. A. Williams, A. E. Carnes, and C. P. Hodgson, "Plasmid DNA vaccine vector design: impact on efficacy, safety and upstream production," Biotechnology Advances, vol. 27, no. 4, pp. 353370, 2009.

[33] F. Soubrier, B. Cameron, B. Manse et al., "pCOR: a new design of plasmid vectors for nonviral gene therapy," Gene Therapy, vol. 6, no. 8, pp. 1482-1488, 1999.

[34] J. Mairhofer and R. Grabherr, "Rational vector design for efficient non-viral gene delivery: challenges facing the use of plasmid DNA," Molecular Biotechnology, vol. 39, no. 2, pp. 97104, 2008.

[35] C. Y. Szpirer and M. C. Milinkovitch, "Separate-componentstabilization system for protein and DNA production without the use of antibiotics," BioTechniques, vol. 38, no. 5, pp. 775$781,2005$.

[36] A. Yadava and C. F. Ockenhouse, "Effect of codon optimization on expression levels of a functionally folded malaria vaccine candidate in prokaryotic and eukaryotic expression systems," Infection and Immunity, vol. 71, no. 9, pp. 49614969, 2003.
[37] L. Frelin, G. Ahlén, M. Alheim et al., "Codon optimization and mRNA amplification effectively enhances the immunogenecity of the hepatitis C virus nonstructural 3/4A gene," Gene Therapy, vol. 11, no. 6, pp. 522-533, 2004.

[38] J. Zur Megede, M. C. Chen, B. Doe et al., "Increased expression and immunogenicity of sequence-modified human immunodeficiency virus type 1 gag gene," Journal of Virology, vol. 74, no. 6, pp. 2628-2635, 2000.

[39] L. Ramakrishna, K. K. Anand, K. M. Mohankumar, and U. Ranga, "Codon optimization of the Tat antigen of human immunodeficiency virus type 1 generates strong immune responses in mice following genetic immunization," Journal of Virology, vol. 78, no. 17, pp. 9174-9189, 2004.

[40] W. Böhm, A. Kuhröber, T. Paier, T. Mertens, J. Reimann, and R. Schirmbeck, "DNA vector constructs that prime hepatitis B surface antigen-specific cytotoxic T lymphocyte and antibody responses in mice after intramuscular injection," Journal of Immunological Methods, vol. 193, no. 1, pp. 29-40, 1996.

[41] D. M. Klinman, "CpG DNA as a vaccine adjuvant," Expert Review of Vaccines, vol. 2, no. 2, pp. 305-315, 2003.

[42] R. K. DeLong, C. M. Reynolds, Y. Malcolm, A. Schaeffer, T. Severs, and A. Wanekaya, "Functionalized gold nanoparticles for the binding, stabilization, and delivery of therapeutic DNA, RNA, and other biological macromolecules," Nanotechnology, Science and Applications, vol. 3, no. 1, pp. 53-63, 2010.

[43] G. Tavernier, O. Andries, J. Demeester, N. N. Sanders, S. C. De Smedt, and J. Rejman, "mRNA as gene therapeutic: how to control protein expression," Journal of Controlled Release, 2010.

[44] S. Pascolo, "Messenger RNA-based vaccines," Expert Opinion on Biological Therapy, vol. 4, no. 8, pp. 1285-1294, 2004.

[45] J. P. Carralot, B. Weide, O. Schoor et al., "Production and characterization of amplified tumor-derived cRNA libraries to be used as vaccines against metastatic melanomas," Genetic Vaccines and Therapy, vol. 3, article 6, 2005.

[46] B. Scheel, R. Teufel, J. Probst et al., "Toll-like receptordependent activation of several human blood cell types by protamine-condensed mRNA," European Journal of Immunology, vol. 35, no. 5, pp. 1557-1566, 2005.

[47] B. Scheel, S. Aulwurm, J. Probst et al., "Therapeutic anti-tumor immunity triggered by injections of immunostimulating single-stranded RNA," European Journal of Immunology, vol. 36, no. 10, pp. 2807-2816, 2006.

[48] P. Qiu, P. Ziegelhoffer, J. Sun, and N. S. Yang, "Gene gun delivery of mRNA in situ results in efficient transgene expression and genetic immunization," Gene Therapy, vol. 3, no. 3, pp. 262-268, 1996.

[49] S. Espuelas, A. Roth, C. Thumann, B. Frisch, and F. Schuber, "Effect of synthetic lipopeptides formulated in liposomes on the maturation of human dendritic cells," Molecular Immunology, vol. 42, no. 6, pp. 721-729, 2005.

[50] K. S. Korsholm, E. M. Agger, C. Foged et al., "The adjuvant mechanism of cationic dimethyldioctadecylammonium liposomes," Immunology, vol. 121, no. 2, pp. 216-226, 2007.

[51] B. Schell, S. Braedel, J. Probst et al., "Immunostimulating capacities of stabilized RNA molecules," European Journal of Immunology, vol. 34, no. 2, pp. 537-547, 2004.

[52] J.-P. Carralot, J. Probst, I. Hoerr et al., "Polarization of immunity induced by direct injection of naked sequence-stabilized mRNA vaccines," Cellular and Molecular Life Sciences, vol. 61, no. 18, pp. 2418-2424, 2004.

[53] B. S. Zolnik, A. Gonzalez-Fernandez, N. Sadrieh, and M. A. Dobrovolskaia, "Minireview: nanoparticles and the immune system," Endocrinology, vol. 151, no. 2, pp. 458-465, 2010. 
[54] S. McCartney, W. Vermi, S. Gilfillan et al., "Distinct and complementary functions of MDA5 and TLR3 in poly(I:C)mediated activation of mouse NK cells," Journal of Experimental Medicine, vol. 206, no. 13, pp. 2967-2976, 2009.

[55] R. K. DeLong, U. Akhtar, M. Sallee et al., "Characterization and performance of nucleic acid nanoparticles combined with protamine and gold," Biomaterials, vol. 30, no. 32, pp. 64516459, 2009.

[56] A. M. Alkilany and C. J. Murphy, "Toxicity and cellular uptake of gold nanoparticles: what we have learned so far?" Journal of Nanoparticle Research, vol. 12, no. 7, pp. 2313-2333, 2010.

[57] K. K. Sandhu, C. M. McIntosh, J. M. Simard, S. W. Smith, and V. M. Rotello, "Gold nanoparticle-mediated transfection of mammalian cells," Bioconjugate Chemistry, vol. 13, no. 1, pp. 3-6, 2002.

[58] K. L. Aillon, Y. Xie, N. El-Gendy, C. J. Berkland, and M. L. Forrest, "Effects of nanomaterial physicochemical properties on in vivo toxicity," Advanced Drug Delivery Reviews, vol. 61, no. 6, pp. 457-466, 2009.

[59] R. K. DeLong, L. Cillessen, C. Reynolds et al., "Biomolecular triconjugates formed between gold, protamine, and nucleic acid: comparative characterization on the nanoscale," Journal of Nanotechnology, vol. 2012, Article ID 954601, 9 pages, 2012.

[60] M. A. Dobrovolskaia, P. Aggarwal, J. B. Hall, and S. E. McNeil, "Preclinical studies to understand nanoparticle interaction with the immune system and its potential effects on nanoparticle biodistribution," Molecular Pharmaceutics, vol. 5, no. 4, pp. 487-495, 2008.

[61] B. Pan, D. Cui, Y. Sheng et al., "Dendrimer-modified magnetic nanoparticles enhance efficiency of gene delivery system," Cancer Research, vol. 67, no. 17, pp. 8156-8163, 2007.

[62] A. Kroll, C. Dierker, C. Rommel et al., "Cytotoxicity screening of 23 engineered nanomaterials using a test matrix of ten cell lines and three different assays," Particle and Fibre Toxicology, vol. 8, no. 9, 2011.

[63] S. Shah, Y. Liu, W. Hu, and J. Gao, "Modeling particle shapedependent dynamics in nanomedicine," Journal of Nanoscience and Nanotechnology, vol. 11, no. 2, pp. 919-928, 2011.

[64] C. L. Waite, S. M. Sparks, K. E. Uhrich, and C. M. Roth, "Acetylation of PAMAM dendrimers for cellular delivery of siRNA," BMC Biotechnology, vol. 9, no. 38, 2009.

[65] S. K. Sohaebuddin, P. T. Thevenot, D. Baker, J. W. Eaton, and L. Tang, "Nanomaterial cytotoxicity is composition, size, and cell type dependent," Particle and Fibre Toxicology, vol. 7, no. 22, 2010.

[66] R. J. Mumper and Z. Cui, "Genetic immunization by jet injection of targeted pDNA-coated nanoparticles," Methods, vol. 31, no. 3, pp. 255-262, 2003.

[67] L. Yan, Zhao F., S. li, Z. Hu, and Y. Zhao, "Low-toxic and safe anomaterials by surface-chemical design, carbon nanotubes, fullerenes, metallofullerenes, and graphemes," Nanoscale, vol. 3, pp. 362-382, 2011.

[68] B. D. Chithrani, A. A. Ghazani, and W. C. W. Chan, "Determining the size and shape dependence of gold nanoparticle uptake into mammalian cells," Nano Letters, vol. 6, no. 4, pp. 662-668, 2006.

[69] C. M. Goodman, C. D. McCusker, T. Yilmaz, and V. M. Rotello, "Toxicity of gold nanoparticles functionalized with cationic and anionic side chains," Bioconjugate Chemistry, vol. 15, no. 4, pp. 897-900, 2004.

[70] B. D. Chithrani and W. C. W. Chan, "Elucidating the mechanism of cellular uptake and removal of protein-coated gold nanoparticles of different sizes and shapes," Nano Letters, vol. 7, no. 6, pp. 1542-1550, 2007.
[71] Y. Pan, S. Neuss, A. Leifert et al., "Size-dependent cytotoxicity of gold nanoparticles," Small, vol. 3, no. 11, pp. 1941-1949, 2007.

[72] W. H. de Jong, W. I. Hagens, P. Krystek, M. C. Burger, A. J. A. M. Sips, and R. E. Geertsma, "Particle size-dependent organ distribution of gold nanoparticles after intravenous administration," Biomaterials, vol. 29, no. 12, pp. 1912-1919, 2008.

[73] B. Gaihre, M. S. Khil, and H. Y. Kim, "In vitro anticancer activity of doxorubicin-loaded gelatin-coated magnetic iron oxide nanoparticles," Journal of Microencapsulation, vol. 28, no. 4, pp. 286-293, 2011.

[74] A. Hanini, A. Schmitt, K. Kacem, F. Chau, S. Ammar, and J. Gavard, "Evaluation of iron oxide nanoparticle biocompatibility," International Journal of Nanomedicine, vol. 6, pp. 787-794, 2011.

[75] V. Sharma, D. Anderson, and A. Dhawan, "Zinc oxide nanoparticles induce oxidative stress and genotoxicity in human liver cells (HepG2)," Journal of Biomedical Nanotechnology, vol. 7, no. 1, pp. 98-99, 2011.

[76] B. C. Heng, X. Zhao, E. C. Tan et al., "Evaluation of the cytotoxic and inflammatory potential of differentially shaped zinc oxide nanoparticles," Archives of Toxicology, vol. 85, no. 12, pp. 1517-1528, 2011.

[77] R. Roy, A. Tripathi, M. Das, and P. D. Dwivedi, "Cytotoxicity and uptake of zinc oxide nanoparticles leading to enhanced inflammatory cytokines levels in murine macrophages: comparison with bulk zinc oxide," Journal of Biomedical Nanotechnology, vol. 7, no. 1, pp. 110-111, 2011.

[78] Z. Xu, L. Chou, and J. Sun, "Effects of $\mathrm{SiO}_{2}$ nanoparticles on HFL-I activating ROS-mediated apoptosis via p53 pathway," Journal of Applied Toxicology. In press.

[79] J. C.K. Lai, G. Ananthakrishnan, S. Jandhyam et al., "Treatment of human astrocytoma U87 cells with silicon dioxide nanoparticles lowers their survival and alters their expression of mitochondrial and cell signaling proteins," International Journal of Nanomedicine, vol. 5, no. 1, pp. 715-723, 2010.

[80] T. S. Hauck, R. E. Anderson, H. C. Fischer, S. Newbigging, and W. C. W. Chan, "In vivo quantum-dot toxicity assessment," Small, vol. 6, no. 1, pp. 138-144, 2010. 

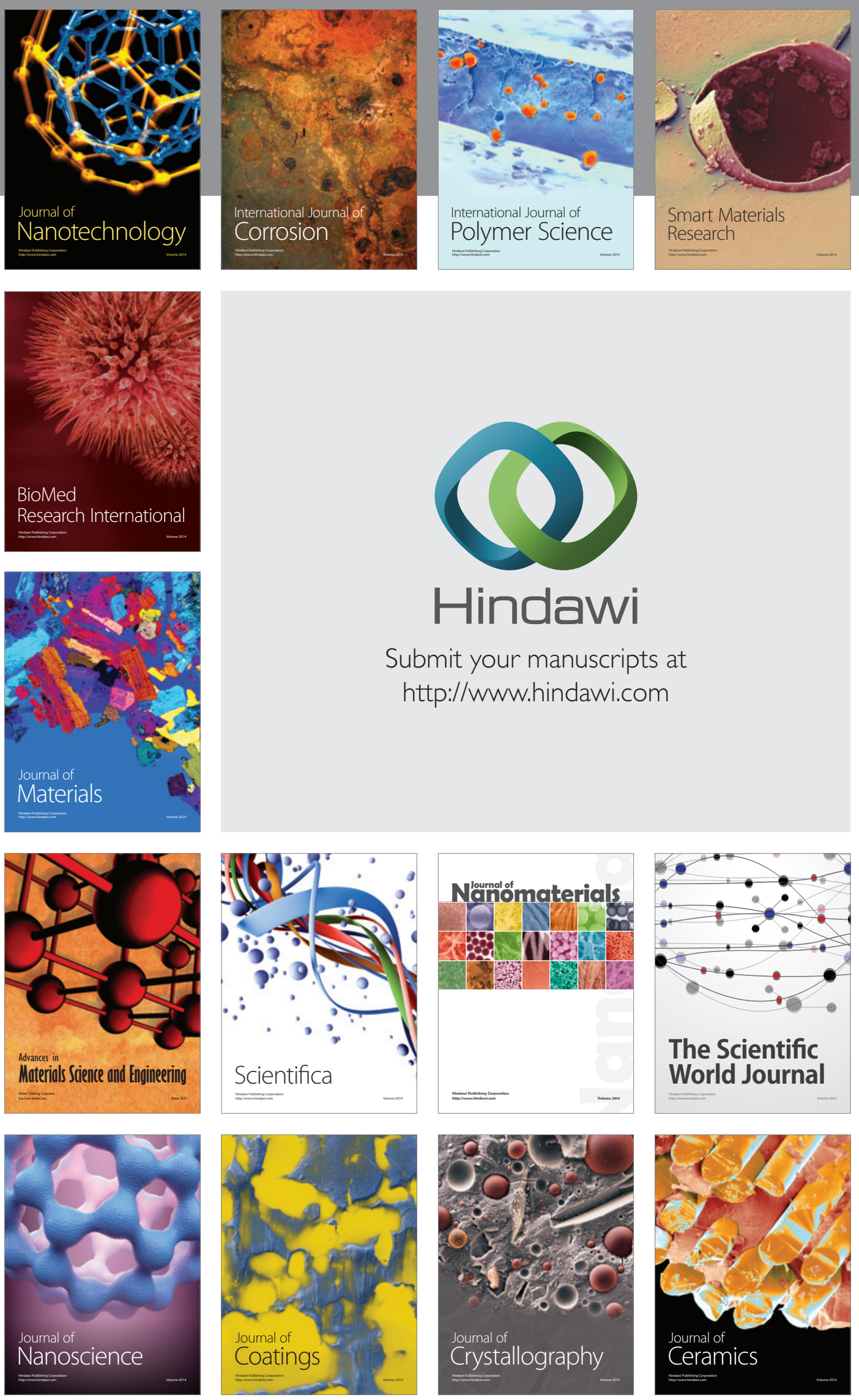

The Scientific World Journal

Submit your manuscripts at

http://www.hindawi.com

\section{World Journal}

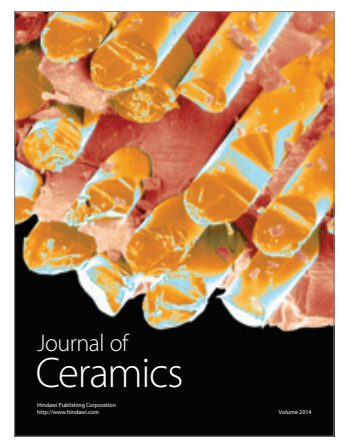

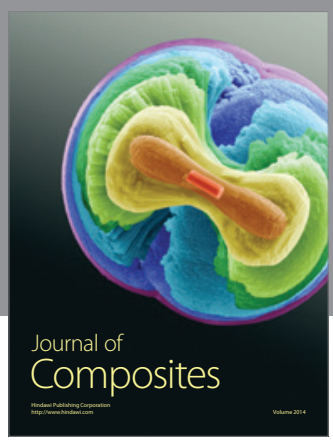
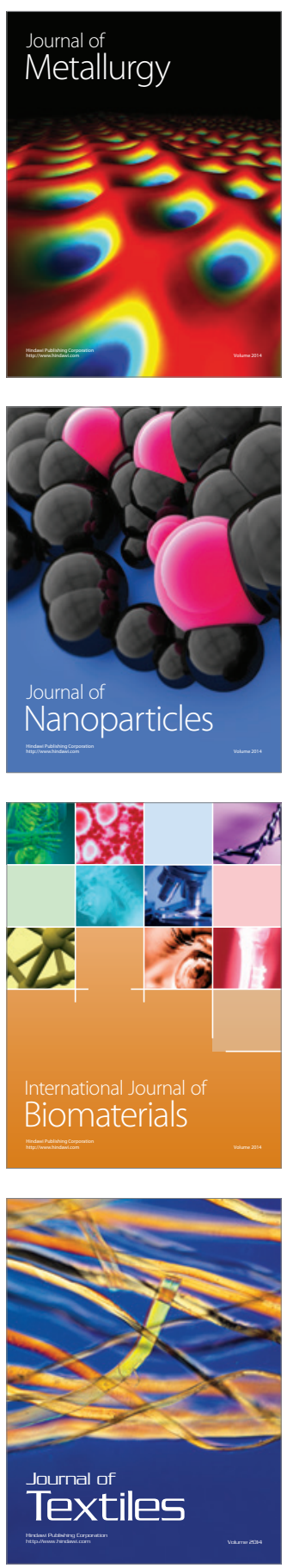